\title{
What do people think about their general practitioners? Survey results comparing public opinion over 40 years from a community in Sydney, Australia
}

\author{
Dr Sisira Edirippulige* \\ Senior Lecturer, Centre for Online Health, The University of Queensland, Brisbane, Australia
}

\begin{abstract}
Objective: The aim of the present study was to examine the changes in the Australian public's perceptions about general practitioners over a 46-year period.

Methods: A cross sectional survey was conducted to examine the perceptions of people regarding their general practitioners. The study replicated a study conducted in 1966 in Sydney, Australia which provided the baseline. The survey was sent by post to residents living in 42 suburbs in Sydney, Australia. Eight hundred electors were randomly selected from the Australian Electoral Rolls as recipients of survey. Analyses were carried out to compare the results of survey with the survey results of baseline study conducted in 1966 .
\end{abstract}

Results: Public perception regarding the doctor's communication skills with patients have improved compared to 1966 . However, the perception of doctors' treatment skills and personal qualities and practice was lower than in 1966. Fewer doctors are perceived as having the wide range of desirable human qualities such as bedside manner, an understanding of human nature, truthfulness and honesty compared with opinions in 1966. Many negative comments were based on personal experience regarding difficulty of obtaining medical care on weekends and at night.

Conclusions: Public perceptions of doctors have changed over the period 1966 to 2012 . These changes may be due to a wide range of socio-economic changes and various shifts taken place in medical profession over 4 decades. The improvement in medical education putting more emphasis on communication may have resulted in doctors better communicating with their patients. Changes such as funding, corporate control of group practices, increasing levels of specialist referrals, high expectation and access to medical information and even the emergence of best practice guidelines may have contributed to a decline in public perceptions of general medical practitioners.

\section{Introduction}

Patient satisfaction has long been considered an important component of care outcomes and it is frequently integrated into evaluation of overall clinical quality [1-3]. Patients' views and perceptions regarding their doctors is a key element in the evaluation of care. Primary care has not been an exception. Various aspects regarding general practitioners have been the focus of such evaluation. Studies have examined, for example, the aspects such as doctors' clinical competency, treatment ability, their communication skills, and personal demeanour. Patients' perceptions of doctors have often been used as an important outcome measure in health care delivery $[4,5]$. Main rationale for examining patients' perceptions of doctors have been the understanding of patients' expectations and concerns. It is widely believed that such understand may offer opportunity for patient-clinician relationship that leads to better health outcomes $[4,6]$. In modern health care where patient-centred care is an important concept, the understanding of patients' views regarding their clinicians should be given a major attention [7-10].

Historically, the medical profession has had a high level of status and social authority [11-14]. Medical profession has consistently been ranked as the highest status of all professions from 1925 when occupational prestige ranking first appeared $[15,16]$. Such ranking reflects academic requirements for entry to the medical profession as well as the technical and moral responsibility attributed to the role of medical practitioner [16]. However, towards to end of the 20th Century, there has been a significant decline in the image, reputation and influence of medical profession. For example, assessing such changes over the 20th Century in the United States, Krause concluded that 'no profession in our sample has flown quite so high in guild power and control as American medicine, and few fallen as fast' [12]. Blendon and colleagues also suggested that the loss of professional legitimacy in American medicine was far more pronounced than that experienced by other social institutions [17]. A study analysing data for 20 -year period (1976-1998) in the US concluded that the attitudes towards physicians in 1998 were significantly more negative when compared to 1976 . The findings suggested that people think 'physicians aren't as thorough as they should be', and 'physicians do not always treat patients with respect' [18].

According to some analysts changes in public perception are due to structural changes in the way medicine is practiced. As McKinlay has pointed out a key aspect of this transformation in the US has been the shift from predominantly fee-for-service system controlled by dominant professionals to a less personalised corporate system controlled increasingly by commercial industry interests.19 A number

Correspondence to: Dr Sisira Edirippulige, Senior Lecturer, Centre for Online Health, The University of Queensland, Brisbane, Australia, Tel: +617 3176 74031; Fax: +61 73176 6945l; E-mail: s.edirippulige@uq.edu.au

Key words: general practice, health services delivery, public opinion, public confidence, trust

Received: June 07, 2017; Accepted: June 27, 2017; Published: June 29, 2017 
of other studies have also outlined the impact of corporatization of doctoring on public attitude [19-22]. The solo medical practitioner has all but disappeared and is now replaced by groups of practitioners who share facilities, patients and who are frequently employees of a corporate entity.

The erosion of public trust in health professionals and health care in the UK has been linked to media scrutiny about scandals over medical competence, inefficiencies of National Health Services' (NHS) finances, increased pressure on NHS budgets due to increase from aged population and rising costs $[23,24]$.

Several studies have examined the patient satisfaction regarding their GPs in Australia. The growth in negative media regarding the medical profession has also been blamed for the growing cynicism towards expert knowledge that is taking place in Australia [25]. Studies published in the early 1990s have reported that medical negligence and involvements in sexual harassment by doctors have tarnished the image of Australian doctors, and may have impacted on public perception of them $[26,27]$. Lupton and colleagues also observed that Australians in professional occupations and tertiary education are becoming more consumerist; and these changes have implications for their opinion of their doctors [25].

However, a number of studies have also shown positive public perception regarding their general practitioners in Australia. These studies have shown that the changing opinions have not affected the belief that doctors are experts in health care that provide a valuable service to the public $[25,28,29]$. Similarly, a study based on the information collected via the Patient Participation Program (PPP) over 10 years (1994-2003) showed patient has high level of satisfaction regarding their general practitioners [30].

Undoubtedly, there have been significant socio-economical changes in Australia over the past 4 decades. Changes in medical profession and medical practice are also apparent. However, no Australian study has attempted to examine the public perceptions of their general practitioners over this period. Understanding of such changes would have practical implications for medical practice, education, policy implementations and patient-centred care. The aim of this study was to investigate changes in the public perception of the Australian doctors between 1966 and 2012. Five key areas in public opinion were evaluated; the cost of receiving care, communication skills, treatment skills, patterns of practice and doctors' personal qualities.

\section{Methods}

\section{Brief description of the 1966 study}

A survey consisted of 56 questions to evaluate the public opinion of general practitioners was conducted in 1966 involving total of randomly selected 479 residents in 42 suburbs which were within a 15-mile radius from the centre for Sydney, New South Wales in Australia [31]. The study does not report the number of the sample and the response rate. Survey was conducted by interviewing one adult from a household.

\section{Survey instrument}

In 2012 study, we used the same survey instrument that was used by Congalton in 1966 in the baseline study [31]. The survey included 56 statements which are descriptions of a general practitioner. Three investigators reviewed the survey questions to assess the relevance in the present study. Decision was made to use the questionnaire without changes. Questions in the survey focused on 5 distinct themes: public's opinion on doctors' concerns about financial matters, doctors' communication skills, medical knowledge and treatment skills, their personal qualities and style of practice. Survey participants were asked to respond to the questions by indicating whether the statements were 'true of all doctors, most doctors, many doctors, or just a few doctors or no doctors. Responses were presented in the Likert scale of 1 to 5 (1-All, 2-Most; 3-Many; 4-Just a Few; 5-None). 3 items were used to collect demographic information of the respondents (gender, age and education level). There were 4 questions to examine respondents' perceptions about doctors' interest in money while 8 questions were asked about communication skills. Ten questions were related to general practitioners' treatment skills and 22 items were asked to assess respondents' perceptions about doctors' personal qualities. Remaining 10 questions were related to participants' perceptions about doctors' patterns of practice.

\section{Recruitment}

In order to the capture the same geographical area covered by the 1966 study, we randomly selected sample of 800 electors from the Australian Electoral Rolls whose Electoral Roll address was in Sydney, New South Wales, Australia. Because the participants were recruited in this study using Australian Electoral Rolls, non-citizens and Australians living in overseas were considered as exclusion criteria. Survey questionnaire was sent to electors by post with a stamped envelope for returning the completed survey. Respondents completed the survey anonymously.

\section{Data analysis}

Mean responses for each item relating to perceptions of participants about their general practitioners were calculated. Responses for each question were counted separately; calculations were carried out using the total responses for each question. Response options from 1 to 2 were aggregated into 1 (All or most); 3 into 2 (Many); 4 to 5 were aggregated into 3 (Few or none) to replicate the scoring used in 1966. To compare responses from the 1966 and 2012 surveys, a series of multinomial logistic regressions were conducted. Data was tested for multicollinearity and goodness of fit and conformed to model assumptions for regression. Data was presented in tables with simple descriptive and odds ratios and confidence intervals. Analysis was undertaken using the statistical package SPSS.

This study was approved by the human ethics committee of the School of Public Health, the University of Queensland, Australia (Approval No: SE081111).

\section{Results}

366 surveys were completed and returned (response rate 47\%). The desirable response rate for survey based research is $60 \%$ which is generally achieved only with multimodal recruitment and follow up of participants (Heberlein, 1978). However response rates as low as $30 \%$ are regularly reported in research. Our response rate of $47 \%$ is acceptable as it did not utilise a multimodal approach. However, the opinions of the non-response group may not be reflected by responders [32].

\section{Demographic characteristics of participants}

Of the 366 participants who responded to the survey 52\% were female. The participants were represented through three age groups. The number of respondents who were either married or lived with a partner was 225. (Table 1) 
Edirippulige S (2017) What do people think about their general practitioners? Survey results comparing public opinion over 40 years from a community in Sydney, Australia

Table 1. Comparison of demographic information 1966 and 2012

\begin{tabular}{|c|c|c|c|}
\hline & & 1966 Study & 2012 Study \\
\hline Total number of participants & & 479 & 366 \\
\hline Response rate & & Not reported & $46 \%$ \\
\hline \multirow{2}{*}{ Gender } & Male & $44 \%$ & $48 \%$ \\
\hline & Female & $56 \%$ & $52 \%$ \\
\hline \multirow{3}{*}{ Age } & $20-39$ yrs & $37 \%$ & $42 \%$ \\
\hline & $40-59$ yrs & $39 \%$ & $35 \%$ \\
\hline & $60 \mathrm{yrs}+$ & $24 \%$ & $23 \%)$ \\
\hline \multirow{2}{*}{ Education level } & Tertiary & Not reported & $211(31 \%)$ \\
\hline & No tertiary & Not reported & $155(42 \%)$ \\
\hline
\end{tabular}

The comparison of respondents' perceptions regarding doctors' interest in financial matters is presented in Table 2.

Compared to 1966, fewer participants perceive that doctors regard their profession as a money-making proposition and that they are driven by money. However, respondents of 2012 survey think that many doctors charge higher fees than they should, and as a result earn more money than is justifiable (Table 2).

Comparison of respondents' perceptions regarding doctors' communication skills is presented in Table 3. Respondents of our survey reported more positive perceptions towards doctors' communication skills compared to 1966 . Respondents in the 2012 survey perceived that fewer doctors use difficult words and expressions; were easier to talk to and they shared information about the patient's condition; provided explanations and open to patients' questions than in the 1966 survey (Table 3).

Perceptions of participants regarding their doctors' medical knowledge and treatment skills are presented in Table 4. Compared to 1966, respondents of 2012 survey think that fewer doctors give medicines which were not needed or give too many pills and injections. Responses to all the other questions show a decrease in confidence in doctors' diagnostic and treatment skills. Respondents in 2012 survey think that fewer doctors make accurate diagnoses, have adequate training, and updated knowledge. Respondents also think fewer doctors are gentle with children and thorough in their investigations (Table 4).

Comparisons of respondents' perceptions regarding doctors' personal qualities is presented in Table 5. Compared to 1966, participants in 2012 survey perceived fewer doctors are impersonal, not caring, impatient, cold and detached and offhand in their manner. However, comparisons of responses from 1966 and 2012 surveys show that fewer doctors now perceived to be sympathetic, happy and cheerful, hardworking, intelligent, tolerant, and as inspiring confidence, honest and having a high code of behaviour (Table 5).

Results relating to patterns of practice and out of hour care are presented in Table 6. Comparison of responses from 1966 and 2012 surveys shows respondents of 2012 believe fewer doctors provide afterhour medical services. Similarly, respondents of recent survey think more doctors refer their patients to specialist services and spend less time with their patients than in 1966 . There is also a perception that more doctors now have too many patients (Table 6).

\section{Discussion}

The current study investigated the perceptions and attitudes of general public in Australia about their primary care doctors while attempting to shed some light on the changes in public opinion occurred over the past 4 decades. The key findings of this study show that the community perception on general practitioners has changed over the past 4 decades. Findings of this study show higher ratings of doctor's communication skills with patients than in 1966. However, the perception of doctors' treatment skills and personal qualities and practice was lower than in 1966. Study results also suggest that fewer doctors are perceived as having the wide range of desirable human qualities such as bedside manner, an understanding of human nature, truthfulness and honesty compared with opinions in 1966 (Table 7).

No doubt that there have been enormous socio-economic and political changes over the past 4-5 decades both within Australia and internationally. The changes occurred in medical profession have also been significant. It is logical to consider that such changes may have had a significant impact on the way public view their doctors [15]. Drastic structural changes implemented to address increasing demand and rising cost of health care have led to privatisation of medical services, changing role of the general practitioners and specialists and growth of emergency department in hospitals [33,34]. There has also been an increase in the general availability of doctors and the number of medical services they provide [34].

Unlike 40 years ago, today doctors working in large general practice centres are mainly employees of large corporations and they are paid by the number of patients they see. This has created a situation where doctors often must work on shorter consultations to accommodate more patients [34]. These pressures may not allow doctors to relate to their patients the same way as doctors did four decades ago. Studies have shown that doctors spend less time today with patients compared to the past. For example, comparing data from 1996 and 2010, the absolute number of longer consultations for children in Australia has decreased [35]. The declining negative evaluation of the personal qualities of doctors may also be a function of changes in attributional power. In the past the role of a doctor was attributed with expertise, sound character and altruistic values. Today's Australian culture relies less on attributional status and power and patients expect a more collaborative power neutral relationship with their doctors. As a result, characteristics such as time spent with a patient, and social skills may be more important for patients in their evaluation of their doctors' capacities and qualities than ever before. It is likely that the reduced time doctors now spend with patients underpins the negative evaluation of personal qualities. A rushed doctor who is required to provide many short consultations over a day will not be perceived as positively as a doctor who has time to talk with their patients and focus on developing relationship with them.

A study that found no changes in public satisfaction over a decade concluded that 'the fact that patient satisfaction did not change in a decade that saw major changes to structure of general practice in Australia such as introduction of accreditation, division of general practice, change in the demography, vocational registration and continuing medical education is itself surprising' [30]. 
Edirippulige S (2017) What do people think about their general practitioners? Survey results comparing public opinion over 40 years from a community in Sydney, Australia

Table 2. Doctors' Interest in Money; comparing 1966 and 2012. 1 = All or most; $2=$ Many; $3=$ Few or none.

\begin{tabular}{|c|c|c|c|c|c|c|}
\hline & & \multicolumn{2}{|c|}{1966} & \multicolumn{2}{|c|}{2012} & \multirow[t]{2}{*}{ OR $(95 \% \mathrm{CI})$} \\
\hline & & $\mathrm{N}$ & $\%$ & $\mathrm{~N}$ & $\%$ & \\
\hline \multirow{3}{*}{ They regard their profession as a money-making proposition } & 1. & 105 & 23 & 53 & 15 & $0.60(0.42,0.88)$ \\
\hline & 2. & 86 & 19 & 71 & 20 & $0.99(0.69,1.42)$ \\
\hline & 3. & 268 & 58 & 223 & 64 & 1 (Ref) \\
\hline \multirow{3}{*}{ They think too much of money } & 1. & 105 & 25 & 54 & 16 & $0.63(0.43,0.91)$ \\
\hline & 2. & 57 & 13 & 59 & 18 & $1.27(0.84,1.90)$ \\
\hline & 3. & 263 & 62 & 215 & 66 & 1 (Ref) \\
\hline \multirow{3}{*}{ They charge fees which are higher than they should be } & 1. & 120 & 28 & 88 & 26 & $1.13(0.81,1.58)$ \\
\hline & 2. & 48 & 11 & 85 & 26 & $2.72(1.82,4.07)$ \\
\hline & 3. & 263 & 61 & 171 & 49 & 1 (Ref) \\
\hline \multirow{3}{*}{ They earn too much money } & 1. & 101 & 24 & 74 & 22 & $1.03(0.72,1.46)$ \\
\hline & 2. & 53 & 13 & 66 & 20 & $1.75(1.16,2.62)$ \\
\hline & 3. & 268 & 63 & 191 & 58 & $1($ Ref) \\
\hline
\end{tabular}

Table 3. Doctor's Communication skills; comparing 1966 and 2012. $1=$ All or most; $2=$ Many; $3=$ Few or none.

\begin{tabular}{|c|c|c|c|c|c|c|}
\hline & & \multicolumn{2}{|c|}{1966} & \multicolumn{2}{|c|}{2012} & \multirow[t]{2}{*}{ OR $(95 \% \mathrm{CI})$} \\
\hline & & $\mathrm{N}$ & $\%$ & $\mathrm{~N}$ & $\%$ & \\
\hline \multirow{3}{*}{ They are very frank in explaining what is wrong with you } & 1. & 201 & 43 & 196 & 55 & $3.04(2.14,4.32)$ \\
\hline & 2. & 77 & 17 & 103 & 29 & $4.17(2.75,6.31)$ \\
\hline & 3. & 187 & 40 & 60 & 27 & 1.00 (ref) \\
\hline \multirow{3}{*}{ They are easy to talk to } & 1. & 283 & 60 & 168 & 46 & $0.78(0.55,1.12)$ \\
\hline & 2. & 96 & 20 & 123 & 34 & $1.68(1.12,2.53)$ \\
\hline & 3. & 96 & 20 & 73 & 20 & 1.00 (ref) \\
\hline \multirow{3}{*}{ They use difficult words and expressions } & 1. & 148 & 31 & 37 & 10 & $0.25(0.17,0.37)$ \\
\hline & 2. & 72 & 15 & 76 & 21 & $1.06(0.73,1.53)$ \\
\hline & 3. & 254 & 54 & 253 & 69 & 1.00 (ref) \\
\hline \multirow{3}{*}{ They do not discuss your illness with you } & 1. & 187 & 41 & 43 & 12 & $0.16(0.11,0.23)$ \\
\hline & 2. & 86 & 19 & 54 & 15 & $0.43(0.29,0.63)$ \\
\hline & 3. & 182 & 40 & 266 & 73 & 1.00 (ref) \\
\hline \multirow{3}{*}{ They don't tell you enough about your condition } & 1. & 177 & 39 & 55 & 15 & $0.26(0.18,0.37)$ \\
\hline & 2. & 86 & 19 & 81 & 22 & $0.78(0.55,1.12)$ \\
\hline & 3. & 187 & 42 & 225 & 63 & 1.00 (ref) \\
\hline \multirow{3}{*}{ They rush things, and don't listen sufficiently to you } & 1. & 77 & 16 & 44 & 12 & $0.72(0.48,1.08)$ \\
\hline & 2. & 91 & 19 & 70 & 19 & $0.96(0.68,1.37)$ \\
\hline & 3. & 307 & 65 & 245 & 69 & 1.00 (ref) \\
\hline \multirow{3}{*}{ They don't explain enough } & 1. & 177 & 38 & 63 & 19 & $0.33(0.23,0.47)$ \\
\hline & 2. & 81 & 17 & 75 & 20 & $0.86(0.59,1.24)$ \\
\hline & 3. & 206 & 45 & 222 & 62 & 1.00 (ref) \\
\hline \multirow{3}{*}{ They discourage people from asking questions } & 1. & 105 & 23 & 26 & 7 & $0.24(0.15,0.39)$ \\
\hline & 2. & 77 & 17 & 54 & 15 & $0.69(0.47,1.02)$ \\
\hline & 3. & 273 & 60 & 276 & 78 & 1.00 (ref) \\
\hline
\end{tabular}

Another important change over the last few decades is the increase of education in general population. Public has become more educated; and they keep updated with new information in a regular basis thanks to new source of information such as the Internet. It is fair to say that this general improvement of education level of people has influenced people to be more critical about their doctors' skills and knowledge as is the case of other professions. Whether the higher rating for doctors' communication skills with patients reflects the greater ease that a more educated population feels in relating with doctors, or whether doctors now have better communication skills is unclear. However, over the last decade in Australia there has been a significant recognition of the need to develop medical student clinical communication skills. So, in this regard findings may reflect changes in training in this area. Public perceptions of doctors' medical knowledge and skills have declined over the past 4 decades. The public thinks that fewer doctors are well trained and up-to-date in medical knowledge. Also, the public believe that fewer doctors are thorough in their investigations. Fewer doctors are perceived to have high personal qualities such as intelligence, truthfulness, honesty, deep understanding of human nature and good bedside manners. In contemporary Australian society patients have never had higher levels of education or access to information as a result of the internet coupled with the expectation that medicine is a purchased consumable service. As a result patients see the relationship with their doctor as more power equal and feel more informed which leads to scepticism of medical judgements and advice. This phenomenon is compounded with very few patients having a sufficient science background to fully understand a diagnosis and treatment implications, and they often rely on simplistic and inaccurate information found online to evaluate their doctor's advice. In this regard patients armed with incomplete information and understanding find more to disagree with doctors about regarding their treatment. Studies have shown that openness of access to professional knowledge eventually erodes the profession's legitimacy and social standing [36,37]. While greater patient engagement and partnership may aid treatment compliance and 
Edirippulige S (2017) What do people think about their general practitioners? Survey results comparing public opinion over 40 years from a community in Sydney, Australia

Table 4. Doctor's Treatment skills; comparing 1966 and 2012. 1 =All or most; $2=$ Many; $3=$ Few or none.

\begin{tabular}{|c|c|c|c|c|c|c|}
\hline & & \multicolumn{2}{|c|}{1966} & \multicolumn{2}{|c|}{2012} & \multirow[t]{2}{*}{ OR $(95 \% \mathrm{CI})$} \\
\hline & & $\mathrm{N}$ & $\%$ & $\mathrm{~N}$ & $\%$ & \\
\hline \multirow{3}{*}{ They are very quick at finding out what is wrong with you } & 1. & 163 & 36 & 98 & 27 & $0.98(0.69,1.39)$ \\
\hline & 2. & 115 & 26 & 160 & 44 & $2.28(1.62,3.21)$ \\
\hline & 3. & 172 & 38 & 105 & 29 & 1.00 (ref) \\
\hline \multirow{3}{*}{$\begin{array}{l}\text { They usually make an accurate diagnosis of what is wrong } \\
\text { with you }\end{array}$} & 1. & 249 & 55 & 173 & 48 & $0.97(0.68,1.39)$ \\
\hline & 2. & 105 & 23 & 119 & 32 & $1.59(1.07,2.37)$ \\
\hline & 3. & 101 & 22 & 72 & 20 & 1.00 (ref) \\
\hline \multirow{3}{*}{ They are able to tell you very quickly about your illness } & 1. & 201 & 45 & 128 & 36 & $0.89(0.64,1.26)$ \\
\hline & 2. & 105 & 23 & 132 & 36 & $1.77(1.24,2.55)$ \\
\hline & 3. & 144 & 32 & 102 & 28 & 1.00 (ref) \\
\hline \multirow{3}{*}{ They like to give you medicine even if you don't need it } & 1. & 96 & 22 & 46 & 13 & $0.59(0.39,0.87)$ \\
\hline & 2. & 57 & 12 & 74 & 21 & $1.59(1.08,2.34)$ \\
\hline & 3. & 292 & 66 & 238 & 66 & 1.00 (ref) \\
\hline \multirow{3}{*}{ They are well trained in medical skills } & 1. & 364 & 83 & 230 & 64 & $0.55(0.33,0.94)$ \\
\hline & 2. & 57 & 13 & 97 & 27 & $1.49(0.82,2.72)$ \\
\hline & 3. & 29 & 4 & 33 & 9 & 1.00 (ref) \\
\hline \multirow{3}{*}{ They are up-to-date in their medical knowledge } & 1. & 316 & 70 & 159 & 46 & $0.39(0.26,0.59)$ \\
\hline & 2. & 81 & 18 & 124 & 35 & $1.19(0.76,1.88)$ \\
\hline & 3. & 53 & 12 & 68 & 19 & 1.00 (ref) \\
\hline \multirow{3}{*}{ They are very gentle with children } & 1. & 359 & 79 & 182 & 56 & $0.30(0.17,0.55)$ \\
\hline & 2. & 72 & 17 & 109 & 34 & $0.89(0.47,1.71)$ \\
\hline & 3. & 19 & 4 & 32 & 10 & 1.00 (ref) \\
\hline \multirow{3}{*}{ They are very thorough in their investigation } & 1. & 283 & 61 & 123 & 34 & $0.39(0.27,0.56)$ \\
\hline & 2. & 96 & 21 & 137 & 39 & $1.29(0.87,1.91)$ \\
\hline & 3. & 86 & 18 & 95 & 27 & 1.00 (ref) \\
\hline \multirow{3}{*}{$\begin{array}{c}\text { They always refer you to another doctor if you need special } \\
\text { treatment }\end{array}$} & 1. & 340 & 74 & 256 & 71 & $0.95(0.59,1.54)$ \\
\hline & 2. & 77 & 17 & 71 & 20 & $1.17(0.67,2.03)$ \\
\hline & 3. & 43 & 9 & 34 & 9 & 1.00 (ref) \\
\hline \multirow{3}{*}{ They give too many pills and injections } & 1. & 115 & 26 & 50 & 15 & $0.35(0.24,0.50)$ \\
\hline & 2. & 62 & 14 & 69 & 20 & $1.21(0.82,1.78)$ \\
\hline & 3. & 244 & 60 & 225 & 65 & $1.00(\mathrm{ref})$ \\
\hline
\end{tabular}

Table 5. Doctors Personal Qualities; comparing 1966 and 2012. 1 = All or most; $2=$ Many; $3=$ Few or none.

\begin{tabular}{|c|c|c|c|c|c|c|}
\hline & & \multicolumn{2}{|c|}{1966} & \multicolumn{2}{|c|}{2012} & \multirow[t]{2}{*}{ OR $(95 \% \mathrm{CI})$} \\
\hline & & $\mathrm{N}$ & $\%$ & $\mathrm{~N}$ & $\%$ & \\
\hline \multirow{3}{*}{ They are too impersonal when talking to you } & 1. & 81 & 18 & 36 & 10 & $0.56(0.36,0.86)$ \\
\hline & 2. & 67 & 15 & 77 & 22 & $1.45(1.00,2.09)$ \\
\hline & 3. & 307 & 67 & 244 & 68 & 1.00 (ref.) \\
\hline \multirow{3}{*}{ They are very sympathetic people } & 1. & 244 & 52 & 130 & 36 & $0.63(0.45,0.87)$ \\
\hline & 2. & 91 & 19 & 117 & 32 & $1.51(1.04,2.19)$ \\
\hline & 3. & 134 & 29 & 114 & 32 & 1.00 (ref.) \\
\hline \multirow{3}{*}{ They are happy and cheerful people } & 1. & 206 & 45 & 82 & 23 & $0.46(0.32,0.66)$ \\
\hline & 2. & 125 & 27 & 158 & 45 & $1.47(1.04,2.08)$ \\
\hline & 3. & 129 & 28 & 111 & 32 & 1.00 (ref.) \\
\hline \multirow{3}{*}{ They are very hard working people } & 1. & 383 & 81 & 227 & 62 & $0.78(0.46,1.29)$ \\
\hline & 2. & 53 & 11 & 110 & 30 & $2.72(1.52,4.88)$ \\
\hline & 3. & 38 & 8 & 29 & 8 & 1.00 (ref.) \\
\hline \multirow{3}{*}{ They don't care a darn about you as a person } & 1. & 72 & 16 & 33 & 9 & $0.52(0.34,0.82)$ \\
\hline & 2. & 57 & 12 & 43 & 12 & $0.86(0.56,1.32)$ \\
\hline & 3. & 32 & 72 & 285 & 79 & 1.00 (ref.) \\
\hline \multirow{3}{*}{ They are very impatient } & 1. & 57 & 12 & 28 & 8 & $0.62(0.38,0.99)$ \\
\hline & 2. & 57 & 12 & 54 & 15 & $1.19(0.79,1.78)$ \\
\hline & 3. & 354 & 76 & 282 & 77 & 1.00 (ref.) \\
\hline \multirow{3}{*}{ They have a deep understanding of human nature } & 1. & 244 & 54 & 90 & 25 & $0.29(0.21,0.41)$ \\
\hline & 2. & 96 & 21 & 123 & 34 & $1.02(0.71,1.46)$ \\
\hline & 3. & 115 & 25 & 145 & 41 & 1.00 (ref.) \\
\hline \multirow{3}{*}{ Doctors are overworked } & 1. & 263 & 57 & 139 & 39 & $0.58(0.42,0.82)$ \\
\hline & 2. & 86 & 19 & 113 & 32 & $1.45(0.99,2.14)$ \\
\hline & 3. & 115 & 24 & 104 & 29 & 1.00 (ref.) \\
\hline
\end{tabular}


Edirippulige S (2017) What do people think about their general practitioners? Survey results comparing public opinion over 40 years from a community in Sydney, Australia

\begin{tabular}{|c|c|c|c|c|c|c|}
\hline \multirow{3}{*}{ They are very intelligent people } & 1. & 388 & 82 & 230 & 64 & $0.50(0.31,0.82)$ \\
\hline & 2. & 53 & 11 & 88 & 25 & $1.41(0.79,2.49)$ \\
\hline & 3. & 34 & 7 & 40 & 11 & 1.00 (ref.) \\
\hline \multirow{3}{*}{ They are very tolerant } & 1. & 283 & 62 & 146 & 42 & $0.53(0.37,0.75)$ \\
\hline & 2. & 91 & 19 & 116 & 33 & $1.30(0.87,1.95)$ \\
\hline & 3. & 91 & 19 & 89 & 25 & 1.00 (ref.) \\
\hline \multirow{3}{*}{ They inspire confidence } & 1. & 263 & 58 & 137 & 38 & $0.53(0.38,0.74)$ \\
\hline & 2. & 91 & 20 & 114 & 32 & $1.28(0.87,1.87)$ \\
\hline & 3. & 110 & 24 & 108 & 30 & 1.00 (ref.) \\
\hline \multirow{3}{*}{ They have good bedside manners } & 1. & 316 & 77 & 138 & 41 & $0.082(0.04,0.15)$ \\
\hline & 2. & 81 & 20 & 125 & 37 & $0.29(0.15,0.55)$ \\
\hline & 3. & 14 & 3 & 74 & 22 & 1.00 (ref.) \\
\hline \multirow{3}{*}{ They are cold and detached in their general attitude } & 1. & 81 & 17 & 28 & 8 & $0.43(0.27,0.69)$ \\
\hline & 2. & 48 & 11 & 57 & 16 & $1.48(0.98,2.26)$ \\
\hline & 3. & 335 & 72 & 267 & 76 & 1.00 (ref.) \\
\hline \multirow{3}{*}{ They give quite a bit of their time free to people who need it } & 1. & 134 & 37 & 49 & 15 & $0.28(0.19,0.41)$ \\
\hline & 2. & 96 & 26 & 90 & 28 & $0.71(0.49,1.02)$ \\
\hline & 3. & 134 & 37 & 178 & 57 & 1.00 (ref.) \\
\hline \multirow{3}{*}{ They are very 'off-hand' in their manner } & 1. & 57 & 12 & 26 & 8 & $0.66(0.41,1.09)$ \\
\hline & 2. & 57 & 12 & 73 & 22 & $1.86(1.27,2.74)$ \\
\hline & 3. & 345 & 76 & 237 & 70 & 1.00 (ref.) \\
\hline \multirow{3}{*}{ Doctors are very truthful and honest people } & 1. & 311 & 68 & 186 & 53 & $0.59(0.39,0.89)$ \\
\hline & 2. & 91 & 20 & 111 & 31 & $1.22(0.77,1.93)$ \\
\hline & 3. & 57 & 12 & 57 & 16 & 1.00 (ref.) \\
\hline \multirow{3}{*}{ They are very humble } & 1. & 115 & 26 & 76 & 23 & $1.17(0.83,1.67)$ \\
\hline & 2. & 57 & 13 & 108 & 32 & $3.36(2.30,4.91)$ \\
\hline & 3. & 268 & 61 & 151 & 45 & 1.00 (ref) \\
\hline \multirow{3}{*}{ They have a high code of behaviour and stick to it } & 1. & 33 & 73 & 187 & 54 & $0.49(0.31,0.76)$ \\
\hline & 2. & 77 & 17 & 112 & 32 & $1.25(0.76,2.06)$ \\
\hline & 3. & 43 & 10 & 50 & 14 & 1.00 (ref.) \\
\hline \multirow{3}{*}{ They have more prestige than they deserve } & 1. & 91 & 20 & 65 & 19 & $0.98(0.68,1.41)$ \\
\hline & 2. & 43 & 10 & 56 & 16 & $1.79(1.16,2.77)$ \\
\hline & 3. & 307 & 70 & 223 & 65 & 1.00 (ref.) \\
\hline \multirow{3}{*}{ They have a good sense of humour } & 1. & 201 & 44 & 54 & 15 & $0.23(0.15,0.33)$ \\
\hline & 2. & 115 & 25 & 133 & 38 & $0.97(0.69,1.36)$ \\
\hline & 3. & 139 & 31 & 166 & 47 & 1.00 (ref.) \\
\hline \multirow{3}{*}{ They have an abrupt manner when speaking to you } & 1. & 48 & 10 & 31 & 9 & $0.85(0.52,1.37)$ \\
\hline & 2. & 81 & 17 & 67 & 18 & $1.09(0.76,1.56)$ \\
\hline & 3. & 340 & 73 & 259 & 73 & 1.00 (ref.) \\
\hline \multirow{3}{*}{ They are happy and cheerful people } & 1. & 206 & 45 & 82 & 23 & $0.46(0.32,0.66)$ \\
\hline & 2. & 125 & 27 & 158 & 45 & $1.47(1.04,2.08)$ \\
\hline & 3. & 129 & 28 & 111 & 32 & 1.00 (ref.) \\
\hline
\end{tabular}

Table 6. Doctors' patterns of practice/out of hours care. 1 =All or most; $2=$ Many; $3=$ Few or none.

\begin{tabular}{|c|c|c|c|c|c|c|}
\hline & & \multicolumn{2}{|c|}{1966} & \multicolumn{2}{|c|}{2012} & \multirow[t]{2}{*}{ OR $(95 \% \mathrm{CI})$} \\
\hline & & $\mathrm{N}$ & $\%$ & $\mathrm{~N}$ & $\%$ & \\
\hline \multirow{3}{*}{ Doctors will openly admit when they don't know what your trouble is } & 1. & 153 & 35 & 76 & 21 & $0.58(0.42,0.81)$ \\
\hline & 2. & 43 & 10 & 78 & 22 & 2.13(1.40,3.24) \\
\hline & 3. & 235 & 55 & 200 & 57 & 1.00 (ref.) \\
\hline \multirow{3}{*}{ They are reluctant to make calls (visits) to your home } & 1. & 101 & 23 & 175 & 55 & 5.11(3.66,7.14) \\
\hline & 2. & 53 & 12 & 43 & 14 & $2.39(1.51,3.79)$ \\
\hline & 3. & 292 & 65 & 99 & 31 & 1.00 (ref.) \\
\hline \multirow{3}{*}{ They are very difficult to get at night or on a Sunday } & 1. & 163 & 40 & 213 & 67 & $4.49(3.11,6.48)$ \\
\hline & 2. & 67 & 16 & 54 & 17 & $2.77(1.73,4.43)$ \\
\hline & 3. & 182 & 44 & 53 & 16 & 1.00 (ref.) \\
\hline \multirow{3}{*}{ They have too many patients } & 1. & 187 & 45 & 163 & 48 & $2.20(1.51,3.23)$ \\
\hline & 2. & 96 & 23 & 126 & 37 & $3.32(2.19,5.02)$ \\
\hline & 3. & 134 & 32 & 53 & 15 & 1.00 (ref.) \\
\hline \multirow{3}{*}{ Too often they refer you to another doctor } & 1. & 48 & 10 & 43 & 12 & $1.28(0.82,1.99)$ \\
\hline & 2. & 38 & 9 & 58 & 16 & $2.18(1.41,3.39)$ \\
\hline & 3. & 359 & 81 & 251 & 72 & 1.00 (ref.) \\
\hline
\end{tabular}


Edirippulige S (2017) What do people think about their general practitioners? Survey results comparing public opinion over 40 years from a community in Sydney, Australia

\begin{tabular}{|c|c|c|c|c|c|c|}
\hline \multirow{3}{*}{ They spend too little time with you as a patient } & 1. & 125 & 27 & 90 & 25 & $1.08(0.77,1.50)$ \\
\hline & 2. & 81 & 18 & 102 & 28 & $1.88(1.33,2.67)$ \\
\hline & 3. & 254 & 55 & 170 & 47 & 1.00 (ref.) \\
\hline \multirow{3}{*}{ They are very careful when prescribing medicine } & 1. & 359 & 82 & 188 & 53 & $0.26(0.17,0.39)$ \\
\hline & 2. & 38 & 9 & 91 & 26 & $1.18(0.69,2.03)$ \\
\hline & 3. & 38 & 9 & 77 & 21 & 1.00 (ref.) \\
\hline \multirow{3}{*}{ They often experiment with you instead of treating you } & 1. & 43 & 10 & 19 & 5 & $0.47(0.27,0.82)$ \\
\hline & 2. & 57 & 14 & 25 & 7 & $0.46(0.28,0.76)$ \\
\hline & 3. & 321 & 76 & 305 & 88 & 1.00 (ref.) \\
\hline \multirow{3}{*}{ They tell you there is nothing much wrong with you, when you feel there is } & 1. & 62 & 15 & 32 & 9 & $0.55(0.35,0.87)$ \\
\hline & 2. & 77 & 18 & 56 & 16 & $0.77(0.53,1.13)$ \\
\hline & 3. & 283 & 67 & 266 & 75 & 1.00 (ref.) \\
\hline \multirow{3}{*}{ They keep you far too long in their waiting rooms } & 1. & 235 & 51 & 169 & 47 & $0.96(0.69,1.33)$ \\
\hline & 2. & 91 & 20 & 91 & 25 & $1.34(0.91,1.98)$ \\
\hline & 3. & 134 & 29 & 100 & 28 & 1.00 (ref.) \\
\hline
\end{tabular}

Table 7. Positive and Negative changes: comparing 1966 and 2012.

\section{Positive changes}

\section{Interest in Money}

- Fewer doctors regard their profession as a money making proposition

- Fewer doctors think too much of money

- when something is wrong

Communication

- More doctors are very frank in explaining what is wrong

- Fewer doctors use difficult words and expressions

- More doctors discuss the illness with their patients

- More doctors tell patients about their condition

- Fewer doctors discourage people from asking questions

- Fewer doctors don't explain enough

\section{Treatment skills}

- Fewer like to give you medicine even if you don't need it

- Fewer give too many pills and injections

\section{Personal qualities}

- Fewer are too impersonal when talking to you

- Fewer don't care a darn about you as a person

- Fewer are very impatient

- Fewer doctors are cold and detached

- Fewer doctors are very off-hand in their manner

- More are very humble

\section{Patterns of practice}

- Fewer doctors experiment with you instead of treating you

- Fewer doctors say nothing is wrong when you feel there is

satisfaction, doctors need to account for these issues in consultations with patients by explaining the treatment rationales and why certain options may or may not be appropriate.

Several similar US studies have shown a significant decline of public perception about doctors' medical knowledge and treatment skills. Comparing data from 3 national surveys over 20 years (19791998), a US based study found that attitudes towards physicians' clinical skills in 1998 were significantly more negative when compared to 1976.

\section{Negative changes}

Interest in Money

- Many doctors charge fees which are higher than they should be

- Many doctors earn too much money
Treatment skills

- Fewer doctors are very quick at finding out what is wrong

- Fewer doctors usually make an accurate diagnosis

- Fewer are able to tell you very quickly about your illness

- Fewer are well trained in medical skills

- Fewer are up-to-date in their medical knowledge

- Fewer are very gentle with children

- Fewer are very thorough in their investigations

- Fewer doctors give their time free to people who need it

Personal qualities

- Fewer are very sympathetic people

- Fewer are happy and cheerful people

- Fewer are very hard working people

- Fewer have a deep understanding of human nature

- Fewer are overworked

- Fewer are very intelligent

- Fewer are very tolerant

- Fewer inspire confidence

- Fewer have good bedside manners

- Fewer are very truthful/honest

- Fewer have a high code of behaviour

- Fewer have a good sense of humour

- Fewer doctors are happy and cheerful people

Patterns of practice

- Fewer doctors admit they don't know what is wrong

- More doctors are reluctant to make calls to your home

- More doctors are difficult to get at night or on a Sunday

More doctors have too many patients

- More doctors too often refer you to another doctor

- More doctors spend too little time with you as a patient

- Fewer doctors are careful when prescribing medicine

18 Another study involving Medicare patients showed there was a significant decline relating to 'thoroughness of examination' [38]. Our finding that there is a decline in the perception for doctor's personal qualities is consistent with previous studies. Pescosolido and colleagues reported that US public think that the doctors' personal qualities have declined over 20 year period (1976-1998). The study revealed that fewer people believed 'doctors showed respect to the patients' and 'doctors did their best to reduce patient worry'.18 Similarly, another 
Edirippulige S (2017) What do people think about their general practitioners? Survey results comparing public opinion over 40 years from a community in Sydney, Australia

study concluded that public thinks doctors do not have adequate level of emotional intelligence [38].

\section{Limitations}

One limitation of this study is related to the survey sample. The survey was sent only to people living in Sydney, therefore the results may not be representative of the entire Australian population. Thus, the findings may not be generalizable. In addition, the findings might reflect the possible biases in the sample with more frequent users, such as those with long-standing illnesses, being overrepresented.

\section{Conclusions}

This study suggests that over the past 4 decades, public trust and confidence in doctors' communication skills has increased while public perceptions of doctors' medical knowledge, treatment skills and personal qualities have declined. These changes may be attributable to a number of significant changes within medical profession, health care systems and society in general. Decline of trust and erosion of confidence in doctors may have implications for the profession as well as patient care. The findings of this study are instructive for both policy makers and the medical profession regarding key areas that warrant attention both in resourcing doctors as well as how to managing a challenging and changing doctor-patient environment.

\section{Acknowledgement}

I thank Professor Jake Najman from the School of Public Health who provided advice and guidance for this study as the supervisor of this research unit in the Masters of Public Health program.

\section{References}

1. Donabedian A (1988) The quality of care: How can it be assessed? Jama 260: 1743-8.

2. Rathert C, Wyrwich MD, Boren SA (2013) Patient-centered care and outcomes: a systematic review of the literature. Med Care Res Rev 70: 351-379. [Crossref]

3. Bjertnaes OA, Sjetne IS, Iversen HH (2012) Overall patient satisfaction with hospitals: effects of patient-reported experiences and fulfilment of expectations. BMJ quality \& safety $21: 39-46$.

4. Cleary PD, McNeil BJ (1988) Patient satisfaction as an indicator of quality care. Inquiry 25: 25-36. [Crossref]

5. Shirley ED, Sanders JO (2013) Patient satisfaction: Implications and predictors of success. J Bone Joint Surg Am 95: e69. [Crossref]

6. Manary MP, Boulding W, Staelin R, Glickman SW (2013) The patient experience and health outcomes. $N$ Engl J Med 368: 201-203. [Crossref]

7. Kupfer JM, Bond EU (2012) Patient satisfaction and patient-centered care: necessary but not equal. JAMA 308: 139-140. [Crossref]

8. Rosenthal GE, Shannon SE (1997) The use of patient perceptions in the evaluation of health-care delivery systems. Med Care 35: NS58-68. [Crossref]

9. Bensing JM, Deveugele M, Moretti F (2011) How to make the medical consultation more successful from a patient's perspective? Tips for doctors and patients from lay people in the United Kingdom, Italy, Belgium and the Netherlands. Patient education and counselling 84: 287-293.

10. Moretti F, Fletcher I, Mazzi MA (2012) GULiVER - travelling into the heart of good doctor-patient communication from a patient perspective: study protocol of an international multicentre study. The European Journal of Public Health 22: 464-9.

11. Brint S (1996) In an age of experts: The changing role of professionals in politics and public life. Princeton University Press.

12. Krause EA (1999) Death of the Guilds: Professions, States, and the Advance of Capitalism, 1930 to the Present. Yale University Press.

13. Larson MS, Larson MS (1979) The rise of professionalism: A sociological analysis. Univ of California Press.
14. Sandel MJ (1998) Democracy's discontent: America in search of a public philosophy. Harvard university press.

15. Hodge RW, Siegel PM, Rossi PH (1964) Occupational prestige in the United States, 1925-63. American Journal of Sociology 286-302.

16. Chartrand JM, Dohm TE, Dawis R, Lofquist LH (1987) Estimating occupational prestige. Journal of Vocational Behavior 31: 14-25.

17. Blendon RJ, Hyams TS, Benson JM (1993) Bridging the gap between expert and public views on health care reform. JAMA 269: 2573-2578. [Crossref]

18. Pescosolido BA, Tuch SA, Martin JK (2001) The profession of medicine and the public: examining Americans' changing confidence in physician authority from the beginning of the'health care crisis' to the era of health care reform. Journal of Health and Social Behavior pp:1-16.

19. McKinlay JB, Marceau LD (2002) The end of the golden age of doctoring. Int J Health Serv 32: 379-416. [Crossref]

20. Mechanic D (2000) Managed care and the imperative for a new professional ethic Health Aff (Millwood) 19: 100-111. [Crossref]

21. McKinlay JB1, Stoeckle JD (1988) Corporatization and the social transformation of doctoring. Int J Health Serv 18: 191-205. [Crossref]

22. Stoeckle JD (2000) From service to commodity: corporization, competition, commodification, and customer culture transforms health care. Croat Med J 41: 141-3.

23. Maynard A, Bloor K (2003) Trust and performance management in the medical marketplace. Journal of the Royal Society of Medicine 96: 532-539.

24. Taylor-Gooby P, Hastie C (2003) Paying for 'World Class' Services: a British Dilemma Journal of Social Policy 32: 271-88.

25. Lupton D (1997) Doctors on the medical profession. Sociology of Health \& Illness 19: 480-97.

26. Lupton D, Chapman S (1991) Death of a heart surgeon: reflections on press accounts of the murder of Victor Chang. BMJ 303: 1583-1586. [Crossref]

27. Chapman S, Lupton D (1994) Freaks, moral tales and medical marvels: health and medical stories on Australian television.

28. Hardie EA, Critchley CR (2008) Public perceptions of Australia's doctors, hospitals and health care systems. Med J Aust 189: 210-214. [Crossref]

29. Potiriadis M, Chondros P, Gilchrist G, Hegarty K, Blashki G, et al. (2008) How do Australian patients rate their general practitioner? A descriptive study using the General Practice Assessment Questionnaire. Medical Journal of Australia 189: 215.

30. Allan J, Schattner P, Stocks N, Ramsay E (2009) Does patient satisfaction of general practice change over a decade? BMC Fam Pract 10: 13. [Crossref]

31. Congalton AA (1969) Public evaluation of medical care. Med J Aust 2: 1165-1171 [Crossref]

32. Fincham JE (2008) Response rates and responsiveness for surveys, standards, and the Journal. American Journal of Pharmaceutical Education p. 72.

33. Collyer F, White K (2001) Corporate control of healthcare in Australia, Australia Institute, Australia.

34. Davies GP, Williams AM, Larsen K, Perkins D, Roland M, et al. (2008) Coordinating primary health care: an analysis of the outcomes of a systematic review. Medical Journal of Australia 188: S65.

35. Freed GL, Spike NA, Sewell JR (2013) Changes in longer consultations for children in general practice. Journal of paediatrics and child health 49: 325-329.

36. Chandratilake M, McAleer S, Gibson J, Roff S (2010) Medical professionalism: what does the public think? Clinical medicine 10: 364-9.

37. Books Z, Adelman I, Morris C. Abbott A (1988) The System of Professions: An Essay on the Division of Expert Labor, Chicago: University of Chicago Press. 15: 225.

38. Safran DG (2003) Defining the future of primary care: what can we learn from patients? Ann Intern Med 138: 248-255. [Crossref]

Copyright: (C2017 Edirippulige S. This is an open-access article distributed under the terms of the Creative Commons Attribution License, which permits unrestricted use, distribution, and reproduction in any medium, provided the original author and source are credited. 